\title{
Video consultations in ordinary and extraordinary times
}

\author{
Callum Duncan, ${ }^{1}$ Angus D Macleod (D) 1,2
}

${ }^{1}$ Neurology, Aberdeen Royal Infirmary, Aberdeen, UK ${ }^{2}$ Division of Applied Health Sciences, University of Aberdeen, Aberdeen, UK

\section{Correspondence to} Callum Duncan, Department of Neurology, Aberdeen Royal Infirmary, Foresterhill, Aberdeen AB25 2ZN, UK; callum.duncan@nhs.net

Accepted 15 June 2020

\section{Check for updates}

(c) Author(s) (or their employer(s)) 2020. No commercial re-use. See rights and permissions. Published by BMJ.

To cite: Duncan C, Macleod AD. Pract Neurol 2020;20:396-403.

\begin{abstract}
Tele-neurology is a neurological consultation at a distance, or not in person, using various technologies to achieve connectivity, including the telephone and the internet. The telephone is ubiquitous and is a standard part of how we manage patients. Video consulting has been used for a long time in some centres, particularly in those where the geography means that patients have to travel long distances. Various technologies can be used, and with the development of various internetbased video-calling platforms, real-time video consulting has become much more accessible. We have provided a tele-neurology service in the North East of Scotland since 2006 using video conferencing with far-end camera control. More recently, we have complemented this using an internet-based platform (NHS Near Me). Here we outline the practicalities of video consulting in 'ordinary' times and comment on its use in the 'extraordinary' times of the coronavirus pandemic.
\end{abstract}

\section{INTRODUCTION}

Technology is ever advancing, smartphones are everywhere and the way people live and interact has changed enormously recently. This is particularly true of the young, but many older people are also embracing new technology. The use of video calling using various platforms has exploded during the current coronavirus disease 2019 (COVID-19) pandemic and has become a lifeline for many in the new norm of social distancing and isolation.

Video consultations are becoming increasingly important for providing neurological services. Face-to-face in-person consultations, allowing a comprehensive neurological examination, will always be the gold standard. ${ }^{1}$ However, video consultations can be effective, convenient and a timesaver for patients, particularly for those who live far from a neurology centre or when a comprehensive examination is not necessary. ${ }^{2-4}$

We provide neurological services to Orkney and Shetland from Aberdeen
Royal Infirmary in the North East of Scotland (figure 1). Travel to Aberdeen for assessment requires a plane or overnight ferry journey, and some patients from the outlying smaller islands may require more than 1 day's travelling time. We set up a tele-neurology service in 2006 to the Balfour Hospital (Orkney) and Gilbert Bain Hospital (Shetland) using video conferencing with far-end camera control, and in 2016 expanded this to include Dr Gray's Hospital in Elgin (65 miles from Aberdeen). We undertake most return appointments by telephone and more recently by NHS Near Me, an internet-based video consultation using the Attend Anywhere platform.

This article focuses on the practicalities of conducting video consultations in 'ordinary times' and in the 'extraordinary times' of COVID-19.

\section{VIDEO CONSULTATION}

There are two main ways to undertake a video consultation:

1. Video conferencing with both near- and farend camera control (figure 2) gives a good quality picture and allows a comprehensive assessment including a directed neurological examination. It requires far-end support from either a trainee doctor or a trained nurse. A good quality video conferencing unit with a screen at either end are connected by a dedicated integrated services digital network (ISDN) line to ensure good picture quality. Internet-based connections such as Jabber $^{\mathrm{TM}}$ using a near-end personal computer and far-end video conferencing unit are possible, but depend on internet bandwidth and 'volume of traffic'; also, the picture quality is not as good due to pixelation when moving the far-end camera.

2. An internet-based video-calling platform that allows the patient to connect into a virtual waiting room using their own computer, laptop, tablet or smartphone. The clinician then connects into the patient from their clinic room or office computer (figure 3). This method is much more 


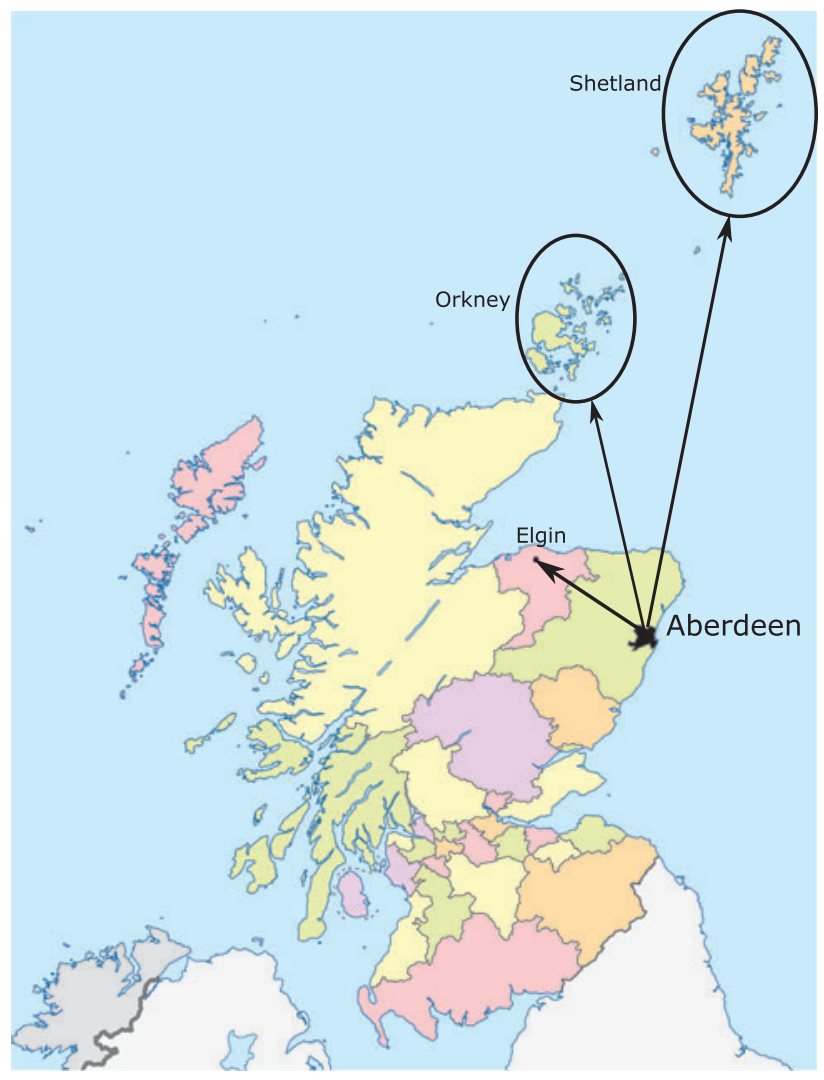

Figure 1 Tele-neurology services from Aberdeen. Image modified from https://commons.wikimedia.org/wiki/File:Scotland, _administrative_divisions_-_Nmbrs_-_colored.svg under the CC BY-SA 3.0 licence.

accessible but lacks the far-end camera control available with video conferencing, and so physical examination is much more challenging.

Practicalities of undertaking a real-time video consultation using video conferencing with near- and far-end control Undertaking a video consultation using dedicated video conferencing requires a near-end unit for the assessing clinician. We have this in our neurology library (figure 2) and use a Cisco video conferencing unit and Phillips monitor. Using a drop-down menu, the near-end clinician dials into equivalent video conferencing equipment in a dedicated clinic room in the peripheral hospital.

The responsibility of the far-end assistant includes receiving the incoming call from the near-end clinician; bringing each patient into the room; retrieving information available only on local IT systems; facilitating a directed neurological examination; assisting the patient out of the clinic room; and arranging for tests to be done locally (bloods, etc). We ensure the patient is informed in advance that they are coming to a video consultation. The near-end clinician, who also ensures the patient can hear and is comfortable, explains the process and informs them that the system is secure and confidential. Technical support is available to us from the NHS Scotland National Video Conferencing Service in real time.

Far-end clinical room set-up

Chairs are positioned to face the far-end video conferencing unit (figure $2 \mathrm{C}$ and $\mathrm{E}$ ) and the couch is angled towards the video conferencing unit to enable remote examination under direction (figure 2B and D). Chairs may need to be moved aside to allow assessment of gait. The far-end camera is controlled by the near-end clinician.

Far-end assistant training

We use a mixture of internal medical trainees, advanced nurse practitioners and specialist nurses as far-end assistants. All doctors at core level should be able to undertake a neurological examination under direction, but in practice, their confidence and skill varies considerably, which may affect the near-end clinician's diagnostic confidence. It is an excellent learning opportunity for the trainee and promotes neurology to corelevel doctors. Because the clinic is undertaken by the near-end clinician, it does not count as a trainee clinic for the purposes of UK neurology training, but the neurologist can facilitate a mini-clinical examination or case-based discussion on the cases seen. Nurses require specific neurological examination training before assisting with the clinic, and involving one or two dedicated nurses can help to build and maintain their skills.

\section{Consultation}

The initial consultation resembles a face-to-face consultation, except that examination is undertaken differently (next section). It is important to look at the camera and to speak clearly. To support discussion at the end of the consultation, the share or presentation function (depending on the video conferencing model) allows the patient to see the near-end clinician's computer screen to review scans, other results or relevant websites. As NHS Orkney and NHS Shetland correspondence, laboratory results and radiology are all available on the NHS Grampian electronic record, the far-end assistant needs to access only limited information from local systems. In Scotland, all radiology is available on a national Picture and archiving communication system, accessible from any health board. Once comfortable using the technology, it is possible to have complex conversations with patients, including breaking bad news.

\section{Neurological examination under direction (box 1)}

The amount of direction required depends on the farend assistant's experience and confidence. It is better to be prescriptive and detailed about the required examination unless the assistant is already experienced in 


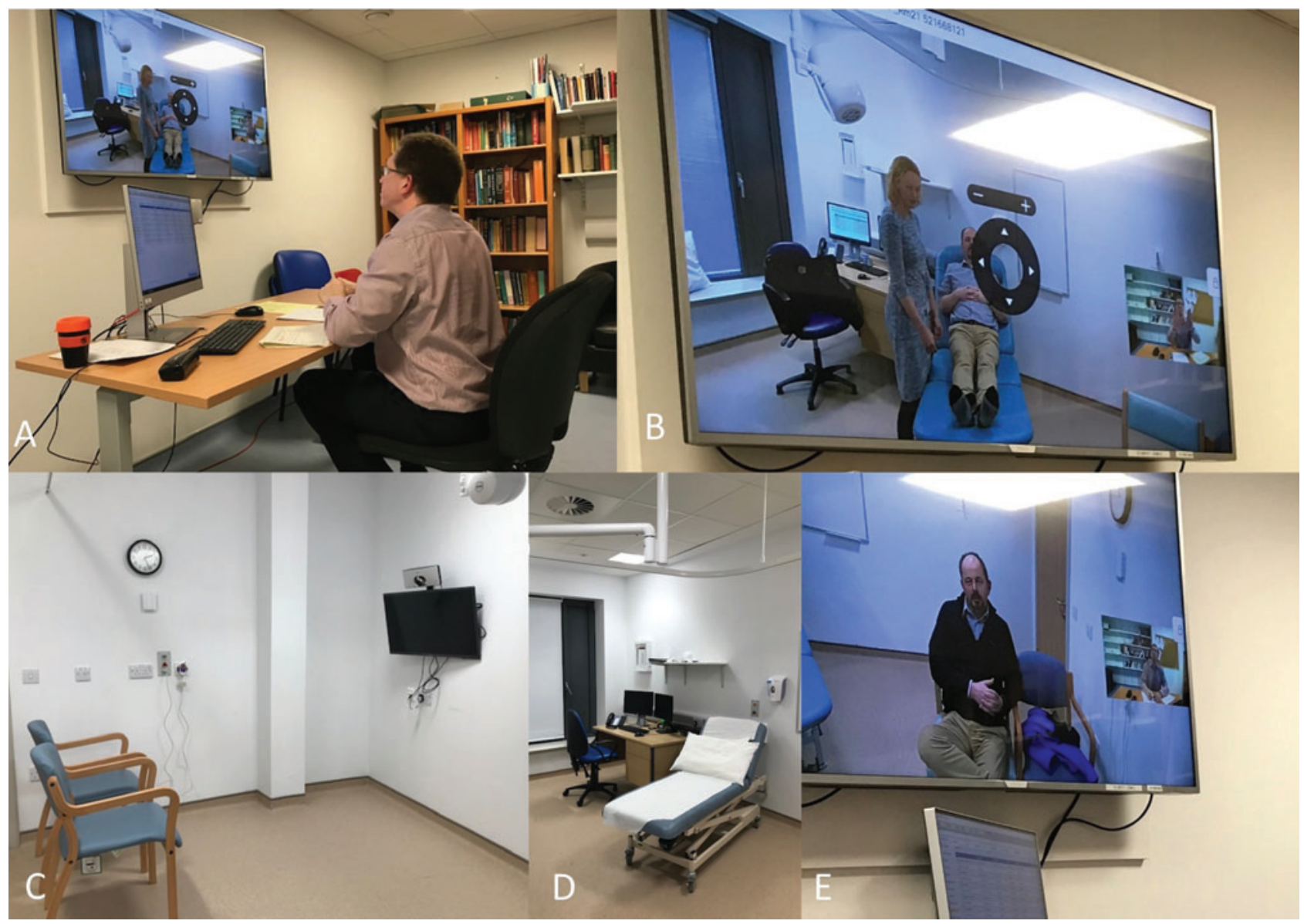

Figure 2 Video consultation using video conferencing: (A) Near-end room set-up, (B) examination by trainee under direction, (C and D) far-end room set up, (E) patient being interviewed.

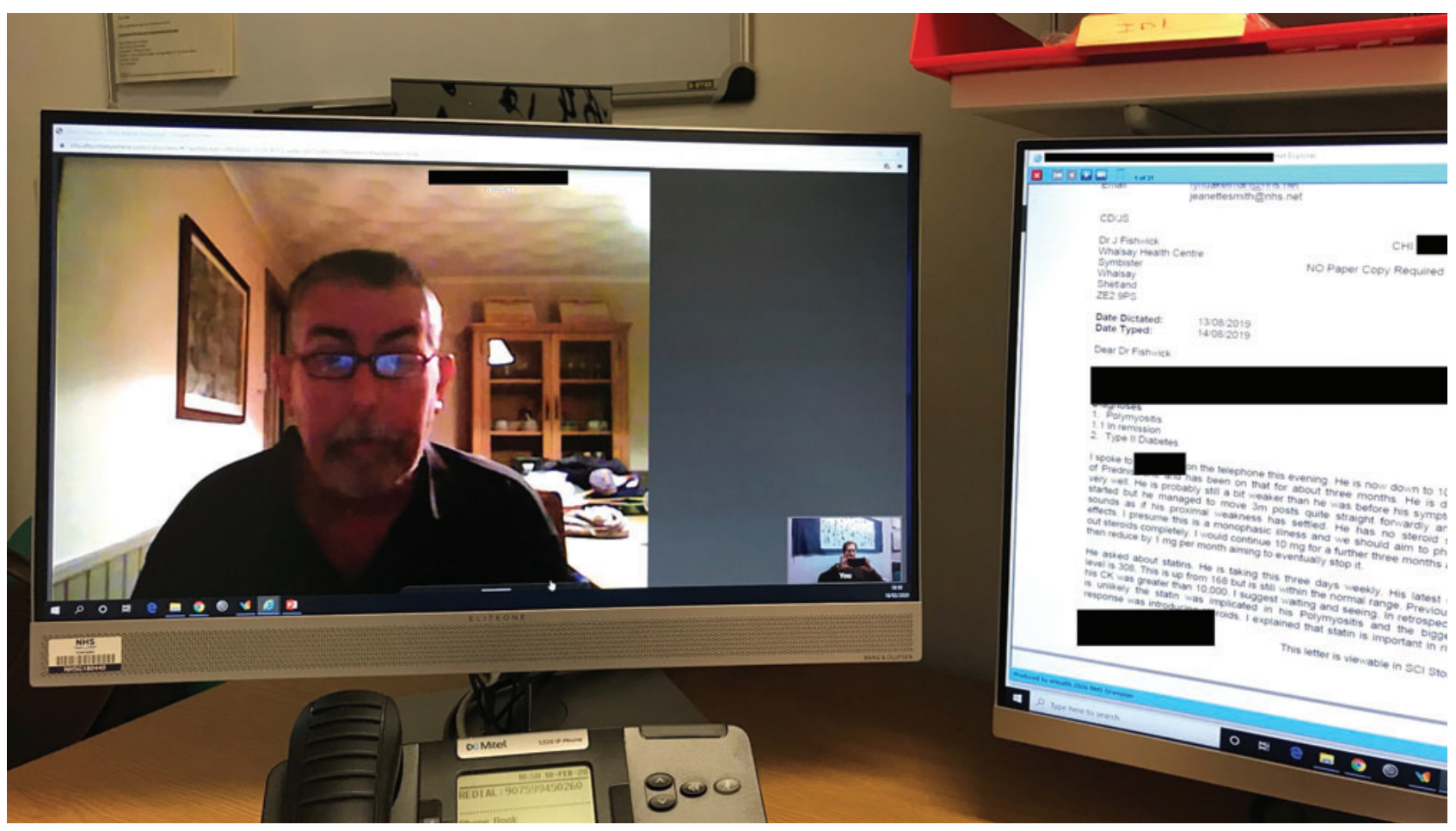

Figure 3 Video consultation using NHS Near Me on the Attend Anywhere platform. 
Box 1 Standard examination under direction in a video consultation using far-end control and an assistant

- Ask the patient to stand and walk to the back of the room (the camera may need to be panned up and a chair moved to give sufficient room). Next assess tandem walking.

- Ask the patient to sit on the couch facing the camera (figure 2B).

- Zoom in to assess pupillary responses including assessment for a relative afferent pupillary defect. The assistant may need to confirm the findings.

- Pan out slightly to assess eye movements by direct instruction to the patient (reminding them to keep their head still) or following the assistant's finger ensuring it is not obscuring your view. The assistant may need to confirm if nystagmus is present.

- The remaining cranial nerves can then be assessed as required. It is not possible to see tongue fasciculation.

- Pan out to examine bradykinesia, tone and power in the upper limbs and then pan further out and down to examine tone and power in the legs and undertake reflexes and plantar responses. It is not possible to see limb fasciculation. We routinely assess shoulder abduction, wrist and finger extension, hip flexion, hip extension and plantar and dorsiflexion. Other muscle groups can be assessed giving clear instructions to the assistant.

- Sensation and coordination can be assessed with the camera in the same position but the camera can be moved to get a better view. Clear instructions should be given. The patient can be seated on the side of the couch to assess for a sensory level if needed.

neurological examination. Broad instructions, such as 'examine the cranial nerves' will leave less experienced assistants uncertain what to do. It is important that the examining assistant does not obscure the view of elicited signs. The far-end camera can be moved up, down, left and right, and zoomed in and out as required.

It is not possible to assess fundi (a retinal photograph taken by a local optician is a good substitute) or to see fasciculation (due to pixelation). Pupillary responses and muscle tone (unless significantly increased) rely on interpretation by the far-end assistant. If reflexes are not seen, this may be due to lack of skill by the examining assistant, although direction can help to improve technique. The Montreal Cognitive Assessment (MoCA) Test Blind is the same as the standard MoCA with visual items removed and can be used for cognitive assessment.

Box 1 outlines a standard examination. This requires a mixture of direct instructions to the patient and direction to the assistant. With adequate clear explanation, it is possible to assess strength in any muscle group; collapsing weakness can be seen and it is possible to elicit a Hoover's sign. Parkinson's disease and myasthenia gravis are often best examined with the patient seated. They are usually straightforward to assess by video conferencing as the most findings are usually easy to see and interpret visually. If the patient attends in a wheelchair and needs to have their gait assessed, the chair can be moved to the back of the room and the patient assessed walking towards the camera with support as necessary.

The key to successful examination under direction is to give clear instructions and to be adaptable. It is important to accept the limitations of the assistant and the technology. Rarely, we have to arrange an inperson review to perform a more-detailed examination. This can be undertaken in either a visiting clinic or in the central hospital to coincide with arranged investigations.

\section{Practicalities of undertaking a real-time video consultation} using an internet-based platform

There are various platforms available for video calling: FaceTime, WhatsApp Messenger, Zoom, Skype, Microsoft Teams, Attend Anywhere, Cliniko, AccuRx and others. Some are set up primarily for social media, some for virtual meetings, and some for clinical use. Information technology (IT) security and encryption are important when considering which medium to use, as patient-identifiable information will be shared, and some platforms may not be secure enough for clinical video consultations. Each organisation's IT security can advise on this, and usually a hospital will have decided already which platform(s) can be used. We use NHS Near Me (using the Attend Anywhere platform), as this is the package used in all Scottish Health boards, and its benefits and challenges are common to all platforms.

The use of Attend Anywhere has increased exponentially during the COVID-19 pandemic. In the week before 'lockdown', there were 330 consultations per week in Scotland. This increased to 10770 consultations per week over only 8 weeks (personal communication, Hazel Archer, Access Program lead for Scottish Government) requiring significant upscaling of IT infrastructure. Attend Anywhere is also available for use in NHS England and NHS Wales, but other platforms are also used.

With Attend Anywhere, patients connect into a virtual clinic using their own computer, tablet or smartphone. In NHS Highland, patients can also attend a staffed NHS Near Me clinic in a local community hospital if they do not have suitable internet access or if they need other clinical support.

Patient experience

Patients are sent a website address to log into. This can either be direct to their general practice or hospital department virtual clinic, or into a managed out-patient 
virtual clinic service where clinic staff greet patients. Access requires use of Chrome or Safari browsers on smartphone, tablet or personal computer. If the patient is unsure about their technology or internet connection, it is helpful to note that if they can make FaceTime, WhatsApp, or Skype video calls, they can use Near Me. The log-in screen takes them through a series of checks ('test my equipment') to ensure connection speed, speaker, microphone and video are all sufficient for the video call. Patients should be encouraged to do this in advance of their appointment day, or clinic staff can do a test call the day before to test that the technology is adequate. The clinic invite letter has a contact telephone number in case of technical difficulties and video conferencing support can contact the patient at a convenient time to work through any technical difficulties. Once connected, they see a picture of themselves while waiting in the virtual waiting room. The clinician then connects in and the appointment starts. There are several useful videos demonstrating this process on YouTube (search NHS Near Me).

\section{Clinician experience}

Connecting to the patient is straightforward. Signing into the login page takes the clinician straight to the appropriate virtual clinic page, which is set up for each department. The appropriate patient is selected from the list and (using the join call function) the clinician connects into the patient in the virtual waiting area, and the consultation starts. Connecting takes about 10 s. If using your office computer it is important to go through the 'test my equipment' function to ensure your microphone and speakers are active. A headset with microphone can be used if required. While it is possible to undertake the video consultation using a single screen, a double screen is preferable as this enables the clinician to see the relevant information in the electronic record at the same time as the patient (figure 3). Because it is not possible to rectify technical issues in real time, it is important to have a back-up plan. If the patient has not connected in or there are significant issues with the connection quality, we quickly revert to the telephone.

Like video conferencing, it is important to look at the camera and to speak clearly, but again, with practice, the consultation unfolds in the usual manner (apart from examination). There is a messaging function if there are technical difficulties with the video or sound, and both the microphone and camera can be turned off by either clinician or patient. The ability to perform a neurological examination is limited as there is no far-end camera control or assistant (see the 'Neurological examination' section). Using the shared screen function, the material displayed on the computer monitor can be reviewed with the patient (figure 4) and a second participant can be invited by email or text

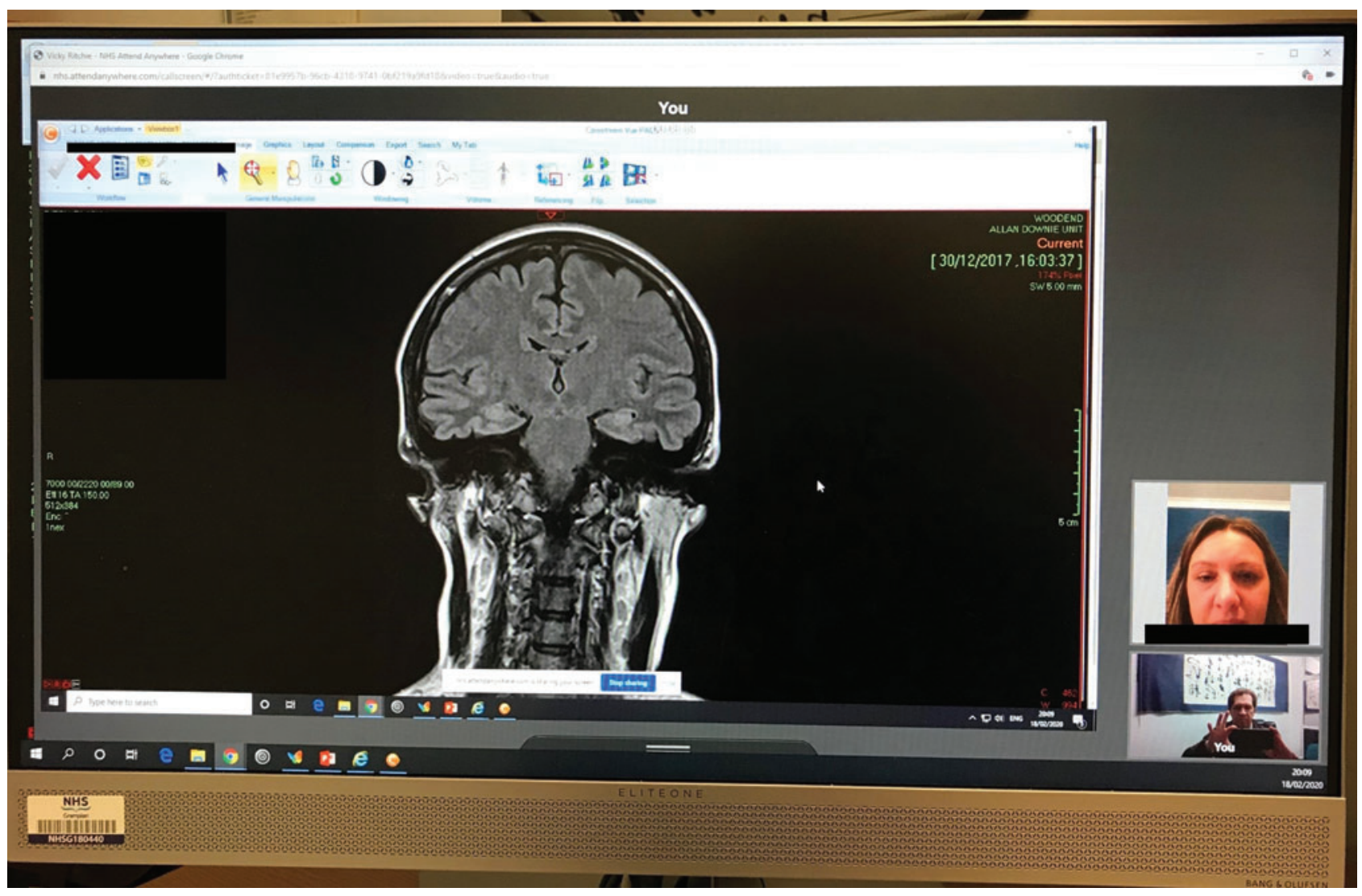

Figure 4 Sharing second screen with PACS open on patient's smartphone. PACS, picture and archiving communication system. 
to connect into the consultation. This allows a relative in another location to join the consultation or a joint consultation with two clinicians in different locations (eg, a prepregnancy planning clinic).

\section{Neurological examination}

As the patient connects from their home or workplace, there is much less control over examination compared to a face-to-face or video conferencing consultation. The picture quality varies from excellent to poor depending on the patient's internet and device. It may also pixelate when the patient moves, reducing the picture quality during examination. Patients often position the device close to themselves, especially if using tablets or smartphones, and the clinician may see only their face (figure 4). They may also call in from a small room with inadequate floor space. To carry out a remote neurological examination ideally, patients need to be sitting in a chair at a table or desk and to have sufficient space behind them to stand and walk. Alternatively, a relative can hold a phone, tablet or laptop about $2 \mathrm{~m}$ away to facilitate examination. Examination is usually limited to what can be observed. Eye movements, facial strength, tongue movement, tremor, bradykinesia and usually gait can be assessed by giving the patient direct instructions. Crude assessment of limb strength is possible if there is a willing relative to assist (figure 5). If the conditions are correct and the relative is confident, a fairly good quality

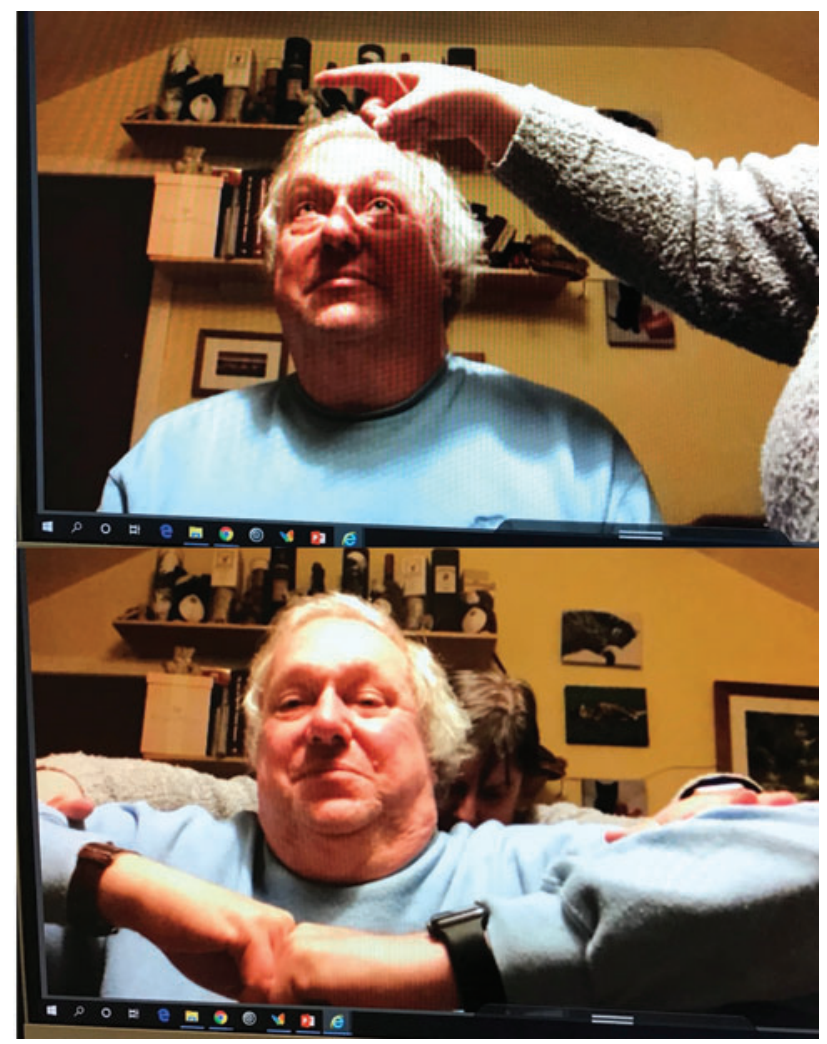

Figure 5 Wife assisting with examination for fatigability in a patient with myasthenia gravis. examination can sometimes be undertaken. Box 2 details a suggested room set-up instruction.

\section{Summary: video consulting in 'ordinary times'}

Table 1 compares the advantages and disadvantages of face-to-face, video and telephone consultations. Face-toface in-person consultations will always be the gold standard. However, video consultation is a useful alternative that is straightforward to learn and, with experience, user friendly. Consultations by video conferencing using a dedicated ISDN line provide the most reliable picture quality and allows a comprehensive neurological examination. It is most useful where travel time is long and costs high. Trained neurologists can learn the technique quickly and it has been shown to be safe and effective. ${ }^{3}$ Patient experience is generally very positive with reduced need to travel the biggest advantage cited (Callum Duncan appraisal patient survey).

Video consulting using internet-based platforms is more widely accessible and uses widely available technology. However, the picture quality depends on the patient's internet connection and device, and neurological examination is more limited. Therefore, it is most suitable for return appointments, particularly where a neurological examination is not required or where there are visible signs of interest. It has clear advantages over telephone consultations and recent studies have shown that it can be effective, easy to use and acceptable to both doctors and patients. ${ }^{4}$

Box 2 Patient instructions before undertaking an internet-based video consultation

- Your upcoming neurology appointment is scheduled to be undertaken by a video consultation. Instructions on how to connect in using your computer, laptop, tablet or smartphone are enclosed. You need to have a reasonable internet connection, but if you can use FaceTime, WhatsApp, Skype or Zoom then you will be able to connect in. Please connect in to the website and use the 'test my equipment' function in advance of your appointment to ensure your internet connection is adequate and that your microphone and speaker work. If there are issues please let us know by phoning the contact number on your instruction sheet. We will be able to advise and may be able to sort the issue for you.

- To make the most out of your appointment, it is best to sit at a table with the computer, tablet or smartphone on the table in front of you. Sit back a bit from the device and if possible, you should have free floor space behind you so that the doctor can watch you walk. There should be enough room to move your chair back to see your arms and hands more easily. It is also useful to have someone with you so that they can provide a witness history and help with some simple examination. 
Table 1 Comparison of advantages and disadvantages of face-to-face, video and telephone consultations

\begin{tabular}{|c|c|c|c|c|c|c|c|}
\hline \multicolumn{2}{|c|}{ Face-to-face consultation } & \multicolumn{2}{|c|}{$\begin{array}{l}\text { Formal video conferencing with } \\
\text { far-end camera control }\end{array}$} & \multicolumn{2}{|c|}{$\begin{array}{l}\text { Internet-based video call } \\
\text { platform }\end{array}$} & \multicolumn{2}{|c|}{ Telephone consultations } \\
\hline Advantages & Disadvantages & Advantages & Disadvantages & Advantages & Disadvantages & Advantages & Disadvantages \\
\hline $\begin{array}{l}\text { Best quality } \\
\text { verbal and } \\
\text { non-verbal } \\
\text { communication }\end{array}$ & $\begin{array}{l}\text { Inconvenience of } \\
\text { attending, } \\
\text { particularly for } \\
\text { patients in remote } \\
\text { areas }\end{array}$ & $\begin{array}{l}\text { Patients need } \\
\text { only to travel to } \\
\text { local hospital }\end{array}$ & $\begin{array}{l}\text { Patients still must } \\
\text { travel to peripheral } \\
\text { hospital }\end{array}$ & $\begin{array}{l}\text { No travel } \\
\text { required }\end{array}$ & $\begin{array}{l}\text { Requires } \\
\text { appropriate device } \\
\text { and good internet } \\
\text { connection }\end{array}$ & $\begin{array}{l}\text { No travel } \\
\text { required }\end{array}$ & $\begin{array}{l}\text { Cannot pick up } \\
\text { on non-verbal } \\
\text { clues }\end{array}$ \\
\hline $\begin{array}{l}\text { No technology } \\
\text { required for } \\
\text { patients }\end{array}$ & $\begin{array}{l}\text { May not be } \\
\text { suitable during } \\
\text { infectious disease } \\
\text { epidemic/ } \\
\text { pandemic }\end{array}$ & $\begin{array}{l}\text { Full control of far- } \\
\text { end camera and } \\
\text { assistant for } \\
\text { examination }\end{array}$ & $\begin{array}{l}\text { Requires expensive } \\
\text { equipment and IT } \\
\text { support }\end{array}$ & $\begin{array}{l}\text { Suitable } \\
\text { devices are } \\
\text { widely } \\
\text { available }\end{array}$ & $\begin{array}{l}\text { More limited } \\
\text { examination } \\
\text { possible }\end{array}$ & $\begin{array}{l}\text { Only } \\
\text { technology } \\
\text { required is } \\
\text { telephone } \\
\text { connection }\end{array}$ & $\begin{array}{l}\text { No examination } \\
\text { is possible } \\
\text { (other than of } \\
\text { speech) }\end{array}$ \\
\hline $\begin{array}{l}\text { Gold standard } \\
\text { examination }\end{array}$ & & $\begin{array}{l}\text { Most } \\
\text { examination is } \\
\text { possible }\end{array}$ & $\begin{array}{l}\text { Not all } \\
\text { examination is } \\
\text { possible }\end{array}$ & $\begin{array}{l}\text { Can share } \\
\text { imaging } \\
\text { with } \\
\text { patients }\end{array}$ & $\begin{array}{l}\text { Some platforms do } \\
\text { not have } \\
\text { necessary } \\
\text { encryption }\end{array}$ & & $\begin{array}{l}\text { Cannot share } \\
\text { imaging with } \\
\text { patients }\end{array}$ \\
\hline \multirow[t]{3}{*}{$\begin{array}{l}\text { Can share } \\
\text { imaging with } \\
\text { patients }\end{array}$} & & $\begin{array}{l}\text { Gives neurology } \\
\text { experience to } \\
\text { trainee doctors/ } \\
\text { specialist nurses }\end{array}$ & $\begin{array}{l}\text { Variable quality of } \\
\text { examining } \\
\text { assistant }\end{array}$ & $\begin{array}{l}\text { Easy to } \\
\text { include } \\
\text { relatives in } \\
\text { discussion }\end{array}$ & $\begin{array}{l}\text { Technical issues } \\
\text { more common; } \\
\text { real-time IT } \\
\text { support not } \\
\text { available }\end{array}$ & & $\begin{array}{l}\text { Difficult to } \\
\text { include relatives } \\
\text { in discussion }\end{array}$ \\
\hline & & $\begin{array}{l}\text { Can share } \\
\text { imaging with } \\
\text { patients }\end{array}$ & $\begin{array}{l}\text { Initially slower } \\
\text { than face-to-face, } \\
\text { but almost as } \\
\text { quick with practice }\end{array}$ & & & & \\
\hline & & & $\begin{array}{l}\text { Rarely technical } \\
\text { issues, but real- } \\
\text { time IT support } \\
\text { available }\end{array}$ & & & & \\
\hline
\end{tabular}

IT, information technology.

\section{Video consulting in 'extraordinary times'}

The social distancing restrictions during the COVID19 pandemic have accelerated the need to incorporate video consulting into neurology outpatient consultations. ${ }^{6}$ Social distancing is likely to remain the norm for some time to come and video consultation will be an important part of the 'recovery' period as we come out of the pandemic. What is acceptable in 'extraordinary' times and 'recovery' is by necessity different from 'ordinary' times. Video consulting by video conferencing with far-end control suffers from the same social distancing restrictions as face-to-face assessment due to the need to attend hospital outpatient clinics.

During the current lockdown period, we have used NHS Near Me to assess new and return patients to limit the number of face-to-face assessments needed in the lockdown period. The exponential increase in the use of Near Me across Scotland initially put considerable strain on the IT infrastructure, but an infrastructure upgrade has resolved most of the issues. Because it provides only limited ability to undertake a suitable neurological examination, it is most suitable for certain new appointments where the neurological examination adds little to the consultation, such as first seizures, epilepsy and headache. For other conditions, it can be used as a screening tool before either a soon or delayed face-to-face assessment to allow a more comprehensive examination. It can be used for most return appointments and for explaining investigation results. If clinicians think detailed neurological examination is essential, the patient still needs either a face-to-face appointment or a video consultation with far-end assistant.

As lockdown restrictions are lifted, internet-based video consultations could be incorporated into standard clinic templates making it easier to incorporate social distancing measures in clinic waiting areas giving reduced footfall. Given the convenience of video consulting, including reducing the need to travel, patients with chronic neurological conditions may want to continue video consulting beyond the 'recovery' period and it may become a standard part of neurology outpatient services.

\section{CONCLUSION}

Video consulting is an efficient, effective and acceptable way to assess selected neurological patients. During lockdown and recovery, it is becoming an integral part of how we provide neurological services. When we return to 'ordinary' times, it has the potential for longlasting changes to how we practise medicine, by improving our patients' experience of the management of chronic neurological conditions. 


\section{Key points}

- With practice, undertaking a video consultation is straightforward, and is often more convenient for the patient.

- Video consulting using a far-end assistant allows the clinician to undertake a relatively comprehensive neurological examination.

- Neurological examination using an internet-based video consultation is more limited, but pertinent aspects of the examination can usually be done.

- The extraordinary times presented by COVID-19 offer an opportunity to reconsider how neurological services are provided; increased use of video consulting in the management of chronic conditions has the potential to improve patient experience.

\section{FURTHER READING}

Larner AJ. Teleneurology: an overview of current status. Pract Neurol 2011;11:283-288.

Acknowledgements We thank the patients and medical trainee for their permission to use their photographs.

Contributors CD conceived the manuscript, wrote the first draft and approved the final version. AM contributed to the content, reviewed and revised the article.

Funding The authors have not declared a specific grant for this research from any funding agency in the public, commercial or not-for-profit sectors.

Competing interests None declared.

\section{Patient consent Obtained.}

Ethical approval information Not required.

Provenance and peer review Commissioned. Externally peer reviewed by Ralph Gregory, Poole, UK.

Map disclaimer The depiction of boundaries on the map(s) in this article does not imply the expression of any opinion whatsoever on the part of BMJ (or any member of its group) concerning the legal status of any country, territory, jurisdiction or area or of its authorities. The map(s) are provided without any warranty of any kind, either express or implied.

ORCID iD

Angus D Macleod http://orcid.org/0000-0002-6284-4239

\section{REFERENCES}

1 Chua R, Craig J, Wootton R, et al. Randomised controlled trial of telemedicine for new neurological outpatient referrals. J Neurol Neurosurg Psychiatry 2001;71:63-6.

2 Larner AJ. Teleneurology: an overview of current status. Pract Neurol 2011;11:283-8.

3 Duncan C, Dorrian C, Crowley P, et al. Safety and effectiveness of telemedicine for neurology outpatients. Scott Med J 2010;55:3-5.

4 Shaw S, Wherton J, Vijayaraghavan S, et al. Advantages and limitations of virtual online consultations in a NHS acute trust: the VOCAL mixed-methods study. Health services and delivery research, no. 6.21. Southampton, UK: NIHR Journals Library, 2018.

5 Donaghy E, Atherton H, Hammersley V, et al. Acceptability, benefits, and challenges of video consulting: a qualitative study in primary care. Br J Gen Pract 2019;69:e586-e594.

6 Nitkunan A, Paviour D, Nitkunan T, COVID-19: switching to remote neurology outpatient consultations. Pract Neurol. 2020; $20: 21618$ 